\title{
High-Throughput Statistical Interrogation of Mechanical Properties with Build Plate Location and Powder Reuse in AISi10Mg
}

\author{
JAY D. CARROLL (1D,,${ }^{1,4}$ ANDREA N. EXIL,${ }^{2}$ STEPHANIE A. DEJONG,${ }^{1}$ \\ ISAAC A. VALDEZ, ${ }^{3}$ CHRISTOPHER M. LAURSEN (D), ${ }^{1}$ \\ LISA A. DEIBLER,${ }^{1}$ CHRISTOPHER B. FINFROCK, ${ }^{1}$ \\ and BRAD L. BOYCE (1) ${ }^{1}$ \\ 1.-Sandia National Laboratories, PO Box 5800, Albuquerque, NM MS 0889, USA. 2.-University \\ of Washington, Seattle, Washington, USA. 3.-University of California-Irvine, Irvine, USA. \\ 4.-e-mail: jcarrol@sandia.gov
}

Additive manufacturing (AM) allows agile, rapid manufacturing of geometrically complex components that would otherwise be impossible through traditional manufacturing methods. With this maturing manufacturing technology comes the need to adopt testing methods that are commensurate with the speed of additive manufacturing and take advantage of its geometric flexibility. High-throughput tensile testing (HTT) is a technique that allows a large number of tensile bars to be tested in a short amount of time. In the present study, HTT is used to evaluate AM AlSi10Mg produced using powder bed fusion with a Renishaw AM250 machine. Three parameters were varied in this study: (1) powder reuse history, (2) location on the build plate, and (3) size of the tensile specimen. For all parameter combinations, at least 22 specimens were tested; in several cases, over 40 were tested. This large dataset, consisting of over 500 tensile tests, permits Weibull statistical analysis and provides sufficient fidelity to isolate subtle trends that would have likely been missed in smaller, traditional datasets. The observed trends are rationalized in terms of the role of porosity and surface crust on mechanical response.

\section{INTRODUCTION}

Additive manufacturing (AM) is capable of producing complex shapes in a rapid, agile, fully digital manufacturing workflow. As a result of AM's growing popularity and widespread usage, there exists a drive to understand how processing parameters affect the mechanical properties of printed components. Lightweight alloys, such as the age hardenable casting alloy AlSi10Mg, are of particular interest in AM. ${ }^{1,2}$ This particular alloy has gained widespread usage because its near-eutectic state suppresses solidification cracking that typically prohibits other aluminum alloys. ${ }^{2}$ Although this alloy exhibits lower strength than its conventionally

(Received July 14, 2021; accepted August 31, 2021;

published online October 18, 2021) manufactured counterparts, such as 6061 and 7075 alloys, ${ }^{3,4}$ the topological optimization of structural components enabled by AM can result in printed components with desirable performance characteristics. ${ }^{5-7}$

Laser powder bed fusion (LPBF), also known as selective laser melting (SLM), or direct metal laser melting (DMLM), represents one of the most common processes for additive manufacturing of metals. The wide range of commercially available printers, the low cost per part, and the fine, submillimeter, feature sizes are some of the attractions of LPBF. In LPBF, much of the powder in the total build volume remains unbound with up to $\sim 90 \%$ of the build volume occupied by unsintered powder.

To reduce waste, unbound powder is often sieved and reused for subsequent prints. ${ }^{8-12}$ Many early studies on the mechanical properties of AM metals neglected to examine the effect of powder reuse. In 
some cases, only fresh (unrecycled) powder was used; in many others, the recycled state was not tracked (Refs. 13-15). The limited literature that does exist on powder recycling provides seemingly contradictory evidence of its effects. In a survey of studies on powder reuse ${ }^{16}$ for $\mathrm{AlSi} 10 \mathrm{Mg}$ and other alloys, there was not a consistent trend in mechanical properties as a function of recycling. In a 2018 study on AlSi10Mg printed at $200{ }^{\circ} \mathrm{C}$, Hadadzadeh et al. ${ }^{17}$ reported that recycling resulted in a minimal improvement in yield strength and a $\sim 10 \%$ increase in ultimate tensile strength compared with virgin samples. However, in another study that year, Del Re et al. ${ }^{18}$ examined mechanical properties as a function of recycling and observed a small, but statistically significant, $3-4 \%$ deterioration of the ultimate tensile strength and yield strength over eight reuse cycles. A key distinction in this apparent contradictory evidence is that the Hadadzadeh study only examined a single tensile bar, whereas the Del Re study averaged the response of six tensile bars for each of the eight recycle builds. Even with averaging, Del Re still reported sporadic behavior between individual builds: while most of the incremental reuse builds showed a decrease in tensile properties, sequential builds 2 and 5 instead showed an increase in tensile properties. From these seemingly inconsistent results, one can conclude that more statistical power is needed to definitively uncover powder reuse effects.

One common effect of powder reuse is an overall increase in sample porosity. ${ }^{19}$ Porosity in AM metals, formed by keyholing, lack-of-fusion, packing gap porosity,$^{20}$ or pre-existing pores in the source powder, is often dependent on the energy density ${ }^{21}$ determined by scan speed ${ }^{22}$ and laser power. The size distribution of the powder and powder chemistry, also play an important role $;^{18,23}$ these factors are influenced by powder reuse. When increased porosity is induced by powder reuse, it is expected to have a deleterious effect on mechanical properties. Regarding modulus, there are well-known rule-ofmixtures models for the deleterious effect of porosity, and such models have been particularly relevant in interpreting AM metal elastic behavior ${ }^{24}$. Regarding strength, a prior study on cast AlSi10Mg ${ }^{25}$ suggests that porosity does not influence yield strength, but the associated cross-sectional pore area was found to correlate with ultimate tensile strength. Regarding ductility, in a rather brittle alloy like $\mathrm{AM} \mathrm{AlSi} 10 \mathrm{Mg}$, pores are expected to serve as failure initiating features, thereby seeding damage nucleation and reducing overall ductility; indeed, multiple empirical models have shown a correlation between increasing porosity and reduced ductility of AM AlSi10Mg. ${ }^{26}$ Similar correlations between porosity and mechanical properties are exhibited in cast aluminum. . $^{25,27,28}$

Porosity, and other heterogeneities formed by LPBF typically lead to more variability in mechanical performance compared with wrought material. ${ }^{15}$ As a result, trends in material properties can be masked by scatter unless a sufficient statistical sampling is collected. Lack of statistical power may contribute to contradicting trends reported in the literature. ${ }^{16}$ While some studies employ intentional statistical assessment of variability (Ref. 18), the total number of tests is often still less than 10 for a given parameter, and even average trends can be obscured. To facilitate efficient collection of statistically significant tensile datasets, we have developed a high-throughput tensile method, capable of reducing the time and cost of tensile testing by a factor of 10 or more. In our previous work, we applied the high-throughput technique to characterize 1000 tensile tests under nominally identical conditions, ${ }^{29}$ assessed the effect of the specimen size on the effective material properties, ${ }^{14}$ and employed the results to identify optimal process parameters. ${ }^{30}$ All those prior studies were performed on $316 \mathrm{~L}$, an alloy with extensive ductility and damage tolerance. Limited work has been done on size dependence of AM AlSi10Mg. ${ }^{31}$

In the present study, we employed a highthroughput tensile test method to efficiently characterize AlSi10Mg. By testing over 500 individual tensile coupons across eight build plates, we were able to examine the effect of powder reuse and build plate location. In addition, we examined sample size effects by comparing 343 tensile bars with a 2.5mm-wide gage section to 176 tensile bars with a $6.25-\mathrm{mm}$ gage section, effectively varying the relative influence of the as-printed surface on observed behavior. Through the analysis of a 3-parameter Weibull distribution we were able to capture consistent trends that would have likely been unclear with fewer tests. Moreover, in some cases we had sufficient data to establish the Weibull threshold values as lower bound property minima. Archimedes' density measurements and Charpy toughness specimens were useful to further our understanding of the observed behavior.

\section{METHODS}

The material studied in this work was aluminum alloy AlSi10Mg containing $10 \%$ silicon and $0.4 \%$ magnesium by weight. For a more detailed description of this alloy, the reader is referred to ASTM Standard F3318-18. ${ }^{32}$ All additive manufacturing was performed on a Renishaw AM250 machine with a $250 \times 250 \mathrm{~mm}$ build plate. Printing was performed with a $130-\mu \mathrm{m}$ hatch spacing, nominal laser power of $200 \mathrm{~W}$ with a $130-\mu \mathrm{s}$ exposure time, and a $70-\mu \mathrm{m}$ spot diameter. Ultra-high purity $(99.999 \%)$ bottled argon was used as a cover gas to maintain oxygen below 100 parts per million. Microstructural properties of the AlSi $10 \mathrm{Mg}$ alloy including grain morphology, texture, and silicon distribution were discussed in our group's previous work. ${ }^{33,34}$ In brief, the material has a moderate $\{100\}$ texture aligned with the build direction. The build plates were 
stress-relief heat treated at $300{ }^{\circ} \mathrm{C}$ for $2 \mathrm{~h}$, a common treatment for this alloy. This heat treatment had the effect of redistributing the silicon from a cellular structure to spherical inclusions..$^{33,34}$

A total of eight build plates were produced, each with an identical geometry and processing condition. The only distinguishing characteristic was the condition of the powder for each build (i.e., powder reuse). A single batch of powder was received from the manufacturer, LPW Technology, Ltd., and opened in an inert environment (argon atmosphere) to divide it into two containers. The first container was used to produce build plates 1 through 5 , with each subsequent build reusing powder after a sieving procedure to remove clusters. The powder did not go through any additional processing before reuse such as a bake-out process to remove moisture ${ }^{35}$ recertifying powder sizes, or recertifying constituent elements. After build 5, the remaining powder from the first container was discarded. The second container was used as source material for builds $6-8$, with build 6 consisting of unused powder, and builds 7 and 8 subsequently reusing the powder. Powder was kept in an argon atmosphere throughout the process. Finfrock et al. ${ }^{36}$ compared properties of specimens printed with the fresh and stored powder as well as hot isostatically pressed specimens.

The dog-bone shaped tensile bars, shown in Fig. 1, were directly printed with the tensile axis aligned with the build direction. No post-print machining was performed other than electrical discharge machining to remove specimens from the build plate. As a result, the tensile bars contained a surface topography that was representative of the

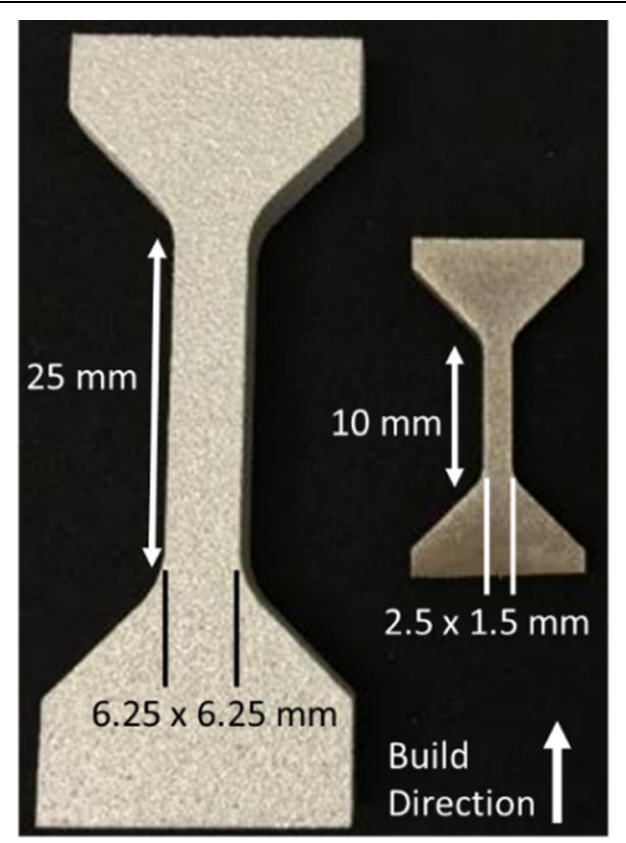

Fig. 1. Geometry of high-throughput tensile bars. The large specimen has a $6.25-\mathrm{mm}$-wide gage section while the small specimen has a $2.5-\mathrm{mm}$-wide gage section. printing process. This high-throughput tensile geometry had been previously produced with 1mm gage width, as described in Salzbrenner et al. ${ }^{15}$. In the present study, the gage width was scaled up by $2.5 \times$ and $6.25 \times$, respectively, and herein referred to as 'small' and 'large,' respectively. Both of these larger geometries, and their ensuing size-dependent tensile properties, have been explored in $316 \mathrm{~L}$ austenitic stainless steel in a previous study. ${ }^{14} \mathrm{In}$ addition to the tensile specimens, eight Charpy specimens were printed vertically on each plate to the nominal dimensions in ASTM standard E23 ${ }^{37}$ and notches were cut using a broach on the asprinted surfaces. A total of 24 large tensile, 50 small tensile, and 8 Charpy specimens were printed on each build plate, in the spatial arrangement shown in Fig. 2. There were also a number of other specimen types and components on the build plate shown but not discussed in this paper. For analysis purposes, the specimen location was tracked and grouped by quadrant (i.e., northeast, northwest, southeast, southwest). These quadrants provide orientation with respect to the gas flow and recoater blade motion, as labeled in Fig. 2.

The density of each large tensile sample was measured by the Archimedes method in deionized water with surfactant to reduce surface tension and bubble formation. An analytical balance was used to measure the mass of specimens and the volume was measured by the weight of water displaced. The density of the water was determined through measurements on a precision ball bearing. The actual density of tensile bars is not as useful for this study as the amount of porosity in samples. For this purpose, relative density of each large tensile bar was calculated using $2.67 \mathrm{~g} / \mathrm{ml}$ as the reference $100 \%$ density (from calculations and manufacturer's reports). The porosity in each sample can be taken as the amount of relative density below $100 \%$.

High-throughput tension testing was performed according to the procedures introduced in Salzbrenner et al. ${ }^{15}$ This technique allows over 200 tension tests to be performed in a single day at a rate of about 2 min per sample (with a quasistatic strain rate around $10^{-3} \mathrm{~s}^{-1}$ ). It uses the dovetail gripping geometry, a camera-based digital image correlation extensometer, streamlined testing software, and batch data processing to improve the efficiency of tensile testing. The result is that statistical distributions of structural properties can be obtained with hundreds of specimens. The cross-sectional area of each large specimen was measured with calipers and each small specimen was measured with a measuring microscope. Parameters were extracted from the measured quasistatic tensile curves, including Young's modulus, yield strength, work hardening rate, ultimate tensile strength, necking strain, and ductility (strain to failure). This study focused only on trends in ductility and ultimate tensile strength. It should be noted that necking strain and yield strength exhibited similar 

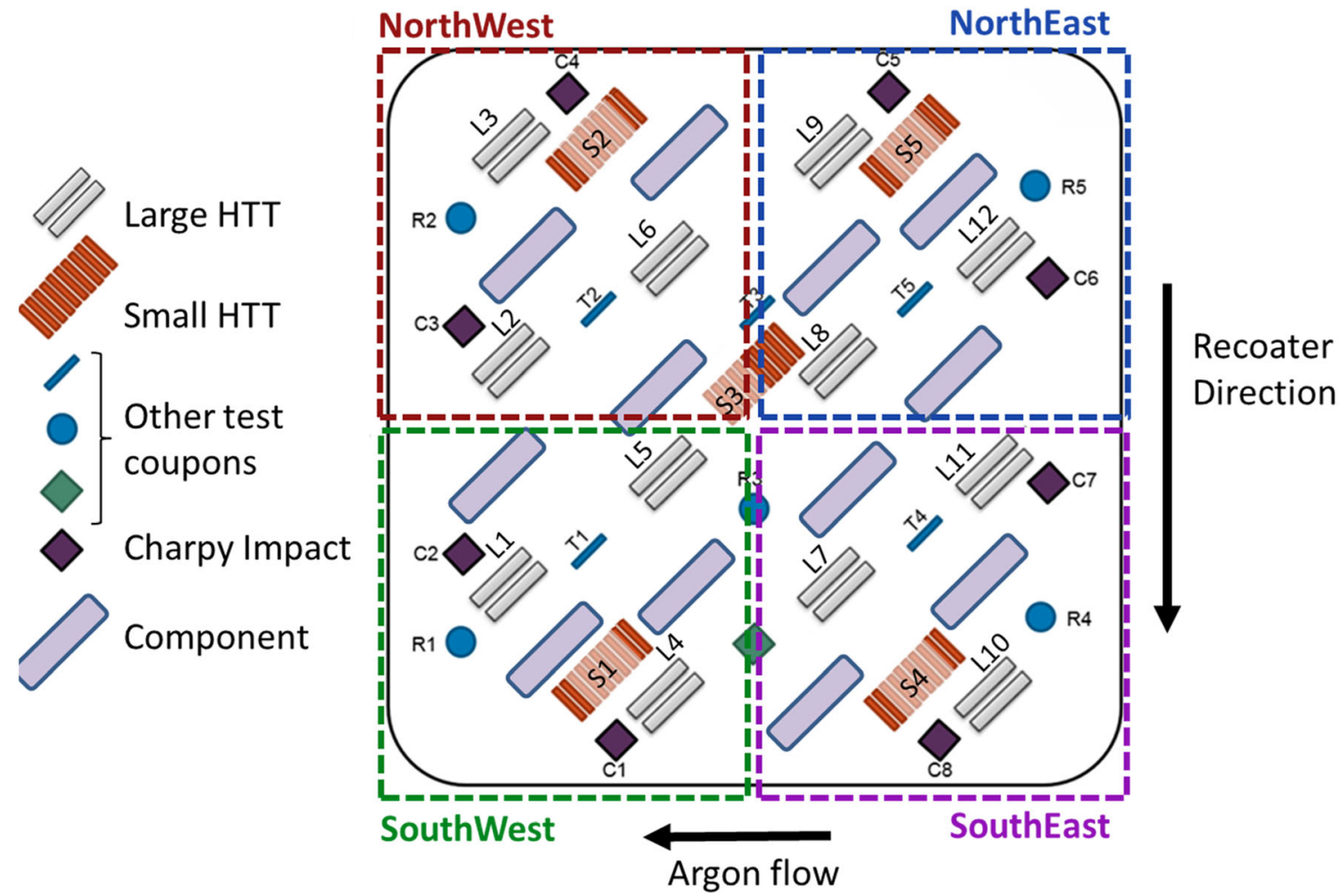

Fig. 2. Geometry for each of the 8 build plates. Two large high-throughput tensile bar specimens were printed at each of 12 locations. Ten small specimens were printed at each of 5 locations. Eight Charpy specimens were printed on each plate. The build plates were divided into four quadrants labeled with cardinal coordinates. The build plate is $250 \mathrm{~mm}$ across (Color figure online).

behavior to these two variables, respectively. Charpy impact toughness experiments were performed in a Satec impact toughness tester.

The ultimate tensile strength and ductility of the tensile bars were analyzed through the 3-parameter Weibull distribution using Minitab21 statistical software with a significance level of five percent. The equation for the 3-parameter Weibull cumulative distribution function (CDF) is given below:

3-parameter Weibull CDF

$$
\mathrm{F}(\mathrm{x})=1-\exp \left[-\left(\frac{\mathrm{x}-\lambda}{\alpha}\right)^{\beta}\right]
$$

where $\mathrm{F}(\mathrm{x})$ is the cumulative probability function at value $\mathrm{x}$, exp is the exponential function, and $\alpha, \beta$, and $\lambda$ are adjustable constants named the scale, shape, and threshold parameters, respectively. ${ }^{38}$ The $\lambda$ parameter was limited to values $\lambda \geq 0$ to prevent physically meaningless negative threshold values. A maximum likelihood estimate of the shape, scale, and threshold (location) of each property is reported, along with an Anderson-Darling goodness-of-fit metric and corresponding $P$-values to determine statistical significance.

\section{RESULTS}

The effect of powder reuse and build-plate location on the relative density is shown in Fig. 3a. The black line connects the average density of each build plate. The observed decrease in density from plate 1 to plate 5 corresponds to sequential powder reuse. The fact that build plate 6 , with ostensibly fresh unrecycled powder (stored in a container for weeks), is considerably less dense than build plate 1 implies that a significant difference exists between powder for builds 1 and 6 . In addition to the powder reuse effect, a significant location effect is also evident in Fig. 3a, with samples in the northern quadrants of the build plate exhibiting higher density than those in the southern quadrants. The potential origins of both the powder reuse and build plate location effects are presented in the Discussion.

Charpy measurements are presented in Fig. 3b. Charpy impact toughness decreases with powder reuse, generally consistent with the density measurements from Fig. 3a with the exception that Charpy value does increase with the re-introduction of unused powder for build plate 6. Charpy toughness also exhibits the same location dependence as density with the northern quadrants of the build 

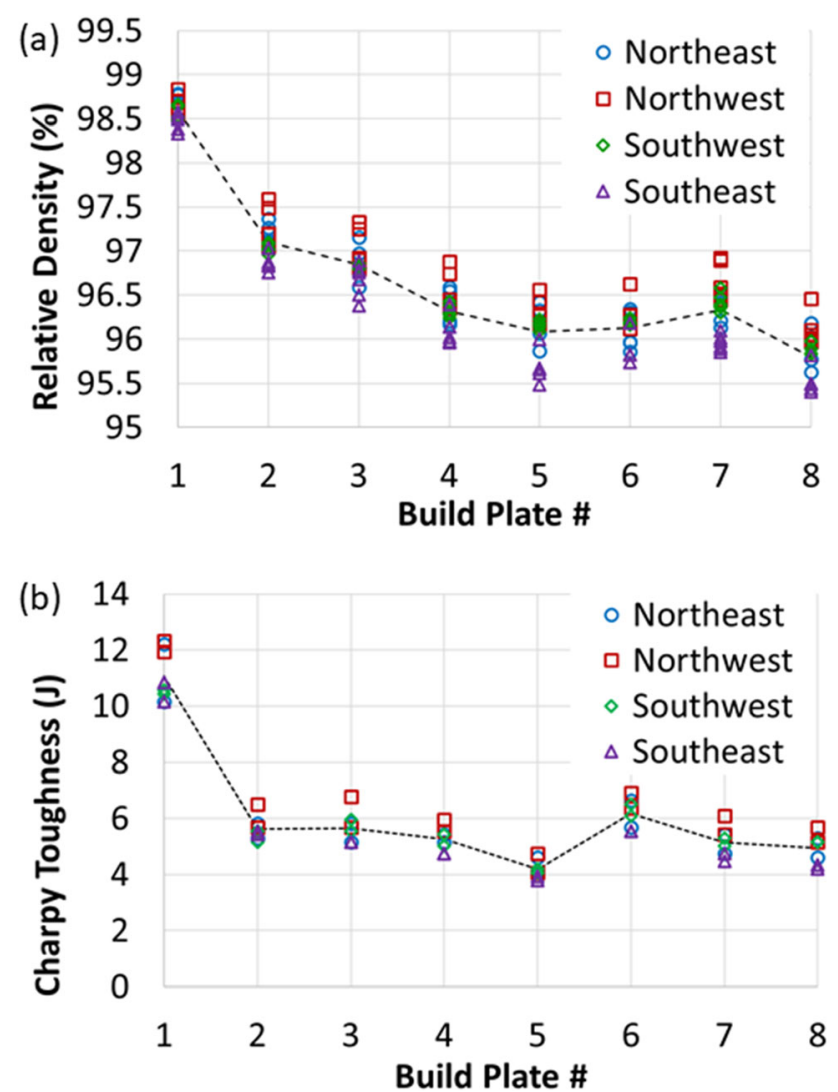

Fig. 3. (a) Relative density of large tensile bars colored by location. The black line connects the average density of each build plate. (b) Charpy impact toughness measurements for 8 specimens on each build plate (Color figure online).

plate being tougher than the southern quadrants. The similar trends between density and Charpy toughness suggest that density, and hence porosity content, may be a driver of toughness.

With over 500 tensile bars, stress-strain curves cannot all be meaningfully placed on a single plot. Instead, Fig. 4 presents stress-strain curves with one row per build plate and separate columns for the two specimen sizes. The result is $\sim 45$ stressstrain curves for small specimens on each build plate and 22 stress-strain curves for large specimens on each build plate. The lines are colored such that shades of red represent build plates from the initial batch of powder and shades of blue represent build plates from the stored powder. Each set of curves has an intentional unload/reload at $1 \%$ strain that was used for more accurate determination of Young's modulus.

Several features are apparent from Fig. 4. First, the ductility of build plate 1 is significantly higher than the other builds. Second, the ductility of small samples shows much more scatter than the ductility of large samples, as might be expected from size and surface crust effects. Third, the apparent/effective strength of small samples is lower than large samples (further details are elucidated through subsequent Weibull analysis). Lastly, a trend that was only clear in the larger samples: build plate 6 appears to show a slight increase in ductility relative to previous build plates.

While the stress-strain curves displayed in Fig. 4 are informative, they are not amenable to making statistical conclusions about mechanical properties. To better understand mechanical property statistics, Weibull cumulative probability distribution plots of ultimate tensile strength (UTS: top) and ductility (bottom) are shown in Fig. 5. These properties are plotted for small (left) and large (right) tensile coupons, with one dataset per build plate. The black horizontal arrow at the bottom of each plot indicates the relative ranking of build plates for the plotted variable. For example, in the top-left plot of Fig. 5, build plate 2 (B2) has the weakest average strength while build plate 1 (B1) has the strongest. On average, ultimate tensile strength and ductility decrease with increasing powder reuse in general agreement with density and Charpy trends shown in Fig. 3. Going beyond average trends, the shapes of the Weibull plots indicate statistical scatter in material response. The Weibull plot for the tensile strength of large build plate 1 specimens is nearly vertical, indicating consistent strengths and a well-defined strength threshold, determined through a best fit to be 212 $\mathrm{MPa}$ (see Table I for a complete compilation of Weibull fit parameters). Such a well-defined strength threshold is particularly useful in engineering design as it suggests a lower bound, worst case property value, below which there is theoretically a zero probability of occurrence. On the other hand, data from build plate 8 (large specimen UTS) in Fig. 5 has a shallower slope. The shallow slope indicates substantial scatter in strength values because the data spans a larger distance along the strength axis. The greater scatter can also be seen by the dashed lines representing 95\% confidence bounds on each data set.

Several observations are apparent concerning ultimate tensile strength statistics from Fig. 5. First, the large specimens have considerably higher minimum strength thresholds compared with the smaller specimens (note the difference in axis scales), likely due to different flaw-to-area ratios. Second, the large specimens have narrower strength distributions than the small specimens. The large specimens have a clearer nonlinearity, indicative of a well-defined non-zero threshold under a 3-parameter Weibull fit. In contrast, the strength distributions for small samples did not exhibit a clear threshold, necessitating a 2-parameter Weibull fit (e.g., threshold strength $=0 \mathrm{MPa}$ ). In other words, based on the $\sim 45$ small tensile tests, we cannot rule out the possible rare existence of very low strength values below $100 \mathrm{MPa}$. Finally, the rank order of build plates is quite different in large specimens vs. small specimens. For example, build plate 2 has the lowest strength of any small specimens, but its large specimens are the third 

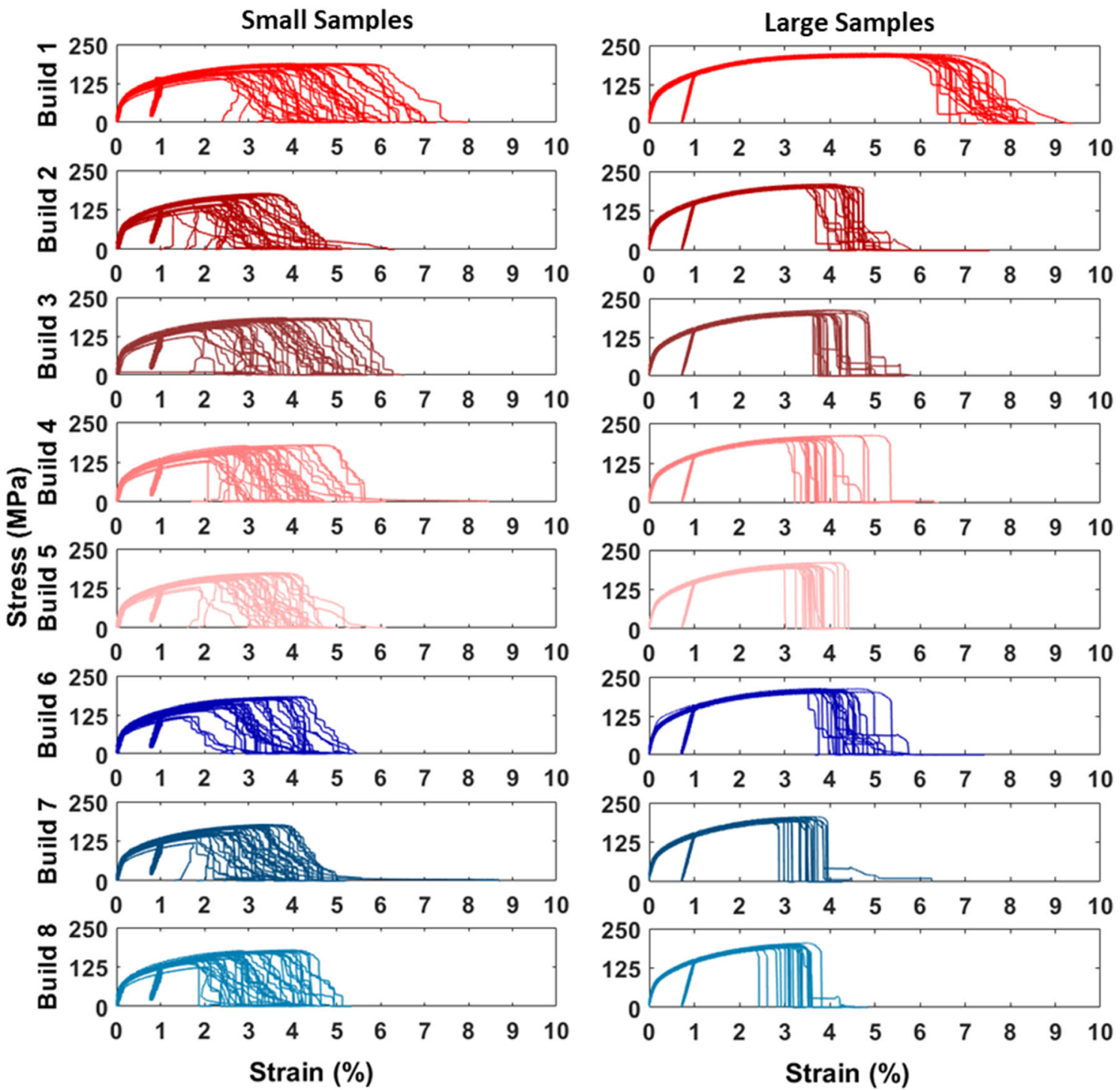

Fig. 4. Stress-strain curves for all small (left) and large (right) specimens, divided by build plate. The first 5 builds (red tones) were printed with one set of powder (with 4 reuses) and the last three (blue tones) were printed with a different set of powder (with two reuses) (Color figure online).

strongest of any build plate. The origins of these size-dependent strength trends are explored further in the Discussion.

Concerning ductility, Fig. 5 also indicates generally poorer effective performance for small samples compared with the larger samples, e.g., lower mean values and broader statistical distributions. The ductilities of most build plates from both sizes fit a 3-parameter Weibull distribution with a defined threshold. The build plate rank ordering for ductility generally follows that of strength: notably build plate 2 has a very large shift in ductility as it did for strength. A notable kink/discontinuity in both the strength and ductility plots are apparent in several of the Weibull plots, regardless of size, around the $50 \%$ level, suggestive of a bimodal property distribution with two subpopulations of similar size. This is likely due to the north-south location dependence, explored further in the Discussion.

As demonstrated in Fig. 3, mechanical properties were found to depend on location within the build plate. To explore this through the lens of Weibull analysis, the tensile strength and ductility data from Fig. 5 Weibull plots were replotted in Fig. 6 with data grouped by location rather than build plate. Generally, samples in the northern quadrants of the build plate were stronger and more ductile than specimens in the southern quadrants. Small tensile samples produced in the centers of build plates show corresponding intermediate levels of strength and ductility. The trends suggest that location relative to recoater blade trajectory (north- 

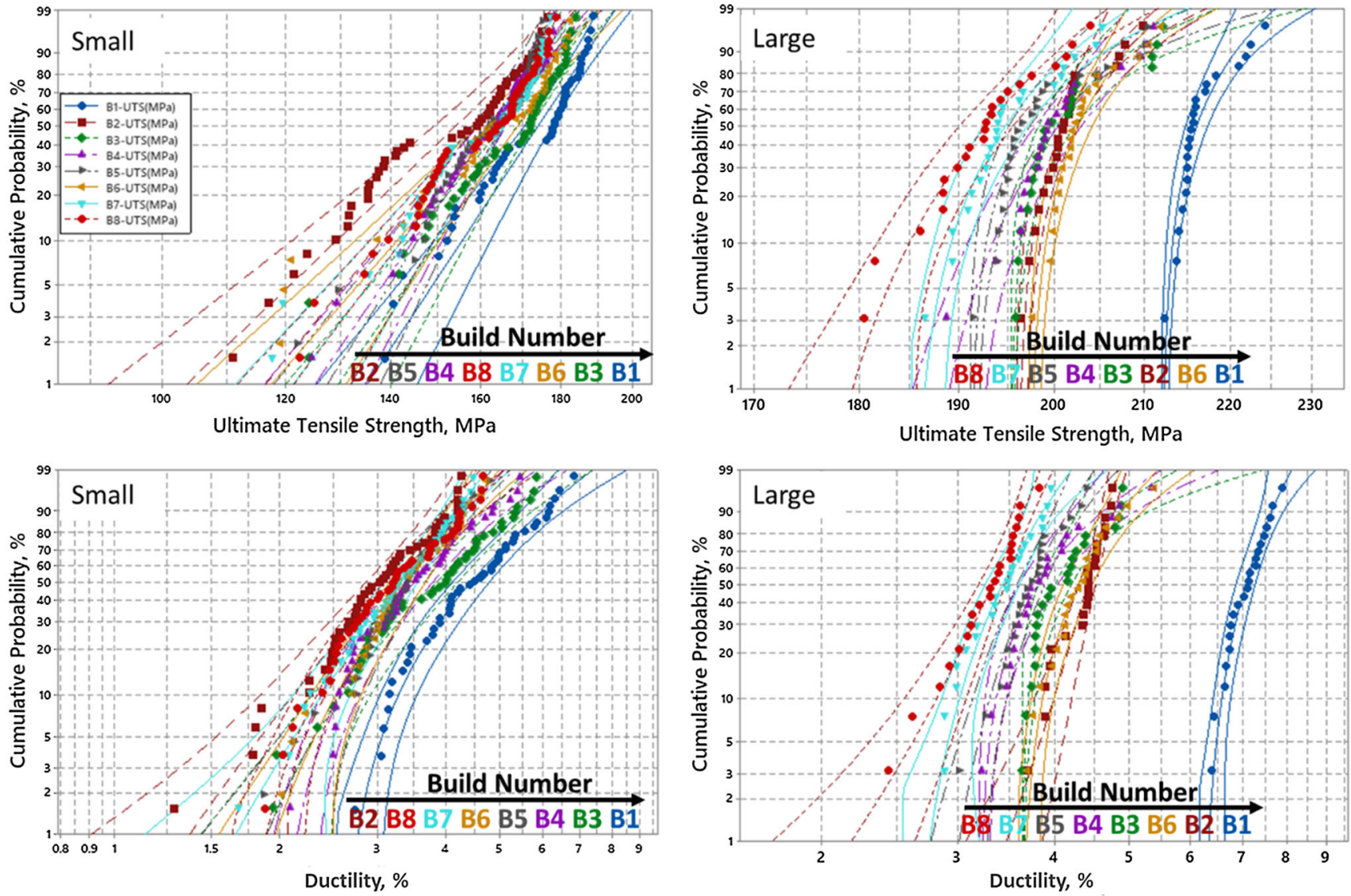

Fig. 5. Weibull plots of ultimate tensile strength (top) and ductility (bottom) for small tensile bars (left) and large tensile bars (right), grouped by build plate. Lines are $95 \%$ confidence intervals (Color figure online).

south axis) had a primary effect on properties, whereas the argon flow (east-west axis) had a measurable but secondary effect.

The Weibull parameters provided in Tables 1 and II provide further quantitative detail behind the aforementioned trends. The $P$-values reported in the rightmost column are the probability of accepting the null hypothesis. Many of these $P$-values do not strictly meet the commonly accepted criterion of $P<0.5$ to reject the null hypothesis. Meeting that criterion requires substantially more data than the amount included in each of these datasets. Still, most of these $P$-values are still reasonable, and give reasonable threshold values, in agreement with the place where the data crosses the horizontal axis on the plots in Figs. 5 and 6 . The only case where the Weibull distribution was consistently called into question was the case of the ultimate strength for small specimens, which gave large negative threshold values. In that case, a threshold value of $0 \mathrm{MPa}$ (i.e., a 2-parameter fit to prevent pathological negative values) was enforced.

The Anderson-Darling goodness-of-fit statistic is also provided in the second column from the right in Tables I and II. This statistic c $^{39-41}$ is one common metric employed to determine whether a sample of observations is found to comply with a specified distribution (Ref. 41 for examples). Its utility has been evaluated previously in the context of a 3parameter Weibull distribution. ${ }^{42}$

Fractographic analysis affords further interpretation of the observed mechanical property trends. Large tensile bars were imaged in high resolution with a Keyence VHX-5000 microscope with both 2D and 3D (height) image stitching. Typical fracture surfaces from a few selected specimens are shown in Fig. 7. To the untrained eye, build plate 1 may appear to have the most porosity due to the large black spots on the fracture surface. On the contrary, as demonstrated in Fig. 3, build plate 1 has the highest density. To resolve this apparent contradiction, one needs to look more closely at the large specimen images in Fig. 7. Many small pores, in the order of $50 \mu \mathrm{m}$ diameter are present in the sample from build plate 7 . These small pores are largely absent from samples in build plate 1 . Another effect visible from the fracture surfaces is the role of the surface crust. The surface crust played a more substantial role in the smaller tensile bars. Even though the sample dimensions were changed, the dimensions of the surface crust remained approximately constant. This surface roughness crust effect is largely responsible for much of the size-dependence observed in AM metals, as we and other 
Table I. Weibull parameters for data grouped by build plate for ultimate tensile strength and ductility

\begin{tabular}{|c|c|c|c|c|c|c|c|}
\hline Small specimens & Build plate & Shape & Scale & Threshold & $\mathbf{N}$ & $\mathbf{A D}$ & $\boldsymbol{P}$ \\
\hline \multirow[t]{8}{*}{ UTS, (MPa) } & 1 & 17 & 178 & 0 & 46 & 1.5 & $<0.010$ \\
\hline & 2 & 11 & 159 & 0 & 45 & 1.2 & $<0.010$ \\
\hline & 3 & 16 & 172 & 0 & 45 & 0.94 & 0.016 \\
\hline & 4 & 16 & 166 & 0 & 45 & 0.31 & $>0.250$ \\
\hline & 5 & 18 & 165 & 0 & 36 & 0.79 & 0.037 \\
\hline & 6 & 13 & 169 & 0 & 36 & 0.79 & 0.038 \\
\hline & 7 & 15 & 166 & 0 & 45 & 1.2 & $<0.010$ \\
\hline & 8 & 15 & 166 & 0 & 45 & 0.84 & 0.028 \\
\hline \multirow{8}{*}{ Ductility (\%) } & 1 & 2.0 & 2.3 & 2.5 & 46 & 0.27 & $>0.500$ \\
\hline & 2 & 4.3 & 3.0 & 0.36 & 45 & 0.41 & 0.273 \\
\hline & 3 & 2.6 & 2.8 & 1.4 & 45 & 0.31 & $>0.500$ \\
\hline & 4 & 2.1 & 1.8 & 1.9 & 45 & 0.26 & $>0.500$ \\
\hline & 5 & 4.0 & 2.5 & 1.1 & 36 & 0.21 & $>0.500$ \\
\hline & 6 & 3.2 & 2.2 & 1.5 & 36 & 0.39 & 0.345 \\
\hline & 7 & 4.4 & 2.9 & 0.65 & 45 & 0.18 & $>0.500$ \\
\hline & 8 & 2.3 & 1.8 & 1.6 & 45 & 0.31 & $>0.500$ \\
\hline \multicolumn{8}{|l|}{ Large specimens } \\
\hline & Build plate & Shape & Scale & Threshold & $\mathbf{N}$ & AD & $\boldsymbol{P}$ \\
\hline \multirow[t]{8}{*}{ UTS, (MPa) } & 1 & 1.6 & 5.0 & 212 & 22 & 0.89 & 0.024 \\
\hline & 2 & 1.6 & 6.1 & 196 & 22 & 0.49 & 0.226 \\
\hline & 3 & 1.2 & 6.6 & 196 & 22 & 0.39 & 0.409 \\
\hline & 4 & 3.1 & 17 & 185 & 22 & 0.62 & 0.081 \\
\hline & 5 & 1.4 & 8.1 & 191 & 22 & 0.76 & 0.49 \\
\hline & 6 & 1.7 & 6.5 & 197 & 22 & 0.46 & 0.28 \\
\hline & 7 & 2.1 & 11 & 185 & 22 & 0.40 & 0.38 \\
\hline & 8 & 3.7 & 22 & 173 & 22 & 0.26 & $>0.500$ \\
\hline \multirow[t]{8}{*}{ Ductility (\%) } & 1 & 2.5 & 1.0 & 6.2 & 22 & 0.27 & $>0.500$ \\
\hline & 2 & 20 & 4.5 & 0 & 22 & 0.59 & 0.119 \\
\hline & 3 & 1.1 & 0.5 & 3.6 & 22 & 0.40 & 0.387 \\
\hline & 4 & 1.4 & 0.8 & 3.2 & 22 & 0.29 & $>0.500$ \\
\hline & 5 & 3.3 & 1.1 & 2.7 & 22 & 0.36 & 0.413 \\
\hline & 6 & 1.9 & 0.8 & 3.6 & 22 & 0.20 & $>0.500$ \\
\hline & 7 & 3.0 & 1.0 & 2.5 & 22 & 0.33 & 0.467 \\
\hline & 8 & 12 & 3.4 & 0 & 22 & 0.25 & $>0.250$ \\
\hline
\end{tabular}

Top, small specimens; bottom, large specimens. $N$ is the number of specimens in each dataset, $A D$ is the Anderson-Darling goodness-of-fit metric, and $P$ is the calculated probability of rejecting the null hypothesis.

researchers have explored previously. ${ }^{14,43,44}$ There are differences in porosity levels and microstructure between these two sizes of tensile bars, but the surface crust appears to be the most likely dominant factor for the differences shown here. The thickness of the surface crust tends to vary from sample to sample, substantially increasing variability as cross-sectional area was reduced; however, no clear surface crust trends were observed with build plate or location.

A three-dimensional projection view of a typical large specimen fracture surface from each build plate is shown in Fig. 8. Tensile specimens from build plate 1 exhibit fracture surfaces with considerable height variation, as is typical for more ductile metals. As density decreased in subsequent build plates, the angle of the fracture surface decreased, suggesting that the fracture surface traversed fewer build layers and likely accommodated less plastic strain. Furthermore, Fig. 8 makes it clear that the black spots on the fracture surface of the build plate 1 specimen are often not all at the same build height. The crack leading to failure took an oblique path to link all of these pores, leading to higher strength and ductility. It should be noted that the pores observed on fracture surfaces are not representative of the overall porosity - rather, the fracture surface often selects the worst-case porosity surface. Moreover, the pores on the surface can be grown during deformation, in the void nucleation-and-growth process. 

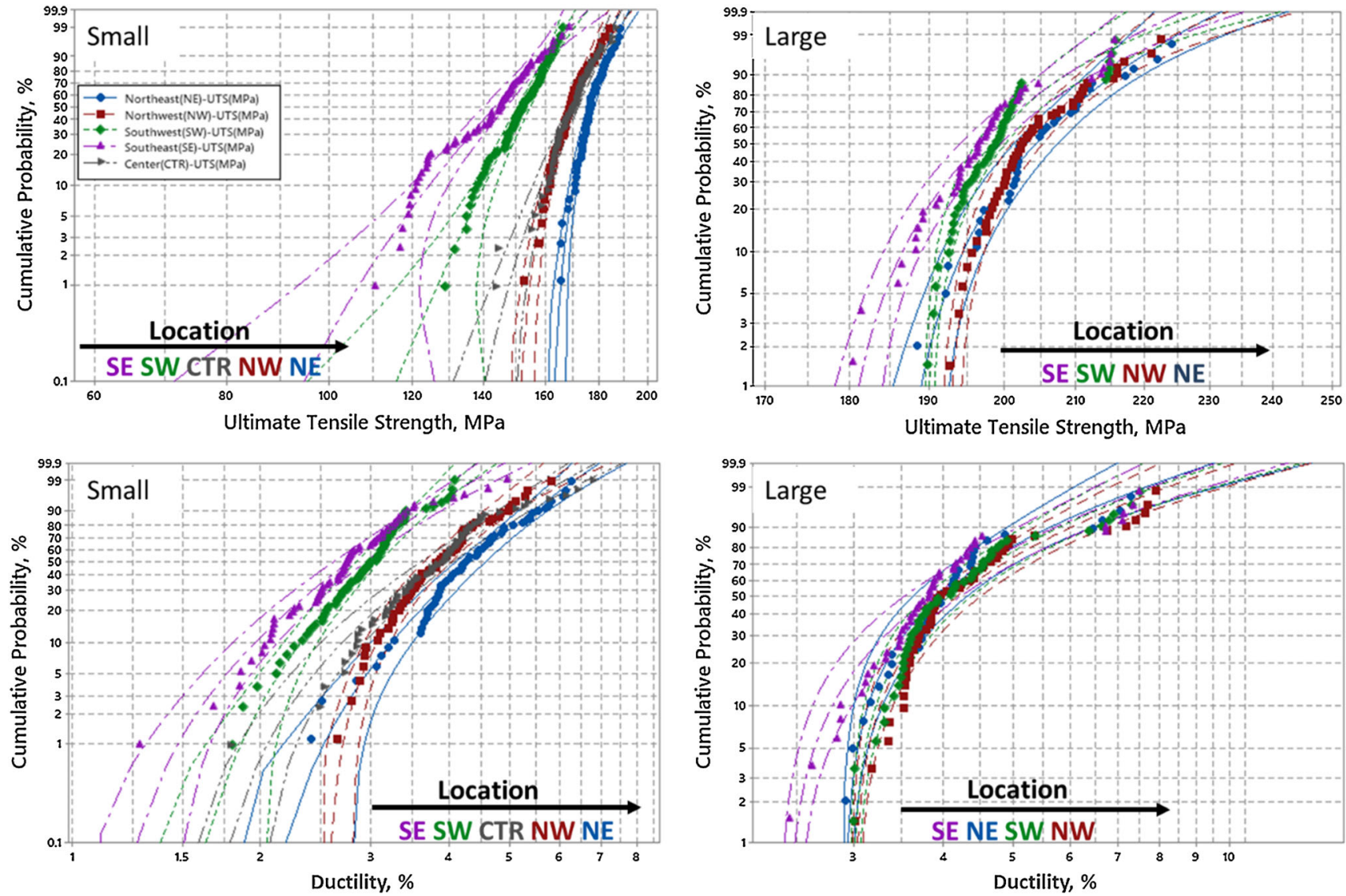

Fig. 6. Weibull plots of ultimate tensile strength (top) and ductility (bottom) for small tensile bars (left) and large tensile bars (right), grouped by location. Comparing these plots with those in Fig. 5 indicates that location is more significant than build plate (powder reuse), especially for small specimens (Color figure online).

\section{DISCUSSION}

\section{Effect of Build-Plate Location}

The results indicated that samples in the northern quadrants of the plate were stronger than those in the southern quadrants. To explore the possible source for this location dependence further, the data was further parsed by individual location for the 12 unique locations of large tensile bars (labeled in Fig. 2 and Fig. 9b), as plotted in Fig. 9a. One clear feature of this plot is the higher strengths of locations 3 and 9 , the two northernmost large tensile bars, contrasted with the low strengths of locations 7,10 , and 11, all in the southeast location. This finer-resolution location comparison not only reinforces the previously reported trends, but further enhances the notion that the very northernmost portion of the build was preferentially strong. It is also interesting that the weakest samples are at location 7 rather than at location 10 , which is the closest to the southeast corner.

While AlSi10Mg build-plate location dependence has rarely been documented, ${ }^{19,20,45}$ the present observed trend is in contrast to anecdotal claims of properties varying with radial distance from the center of a build plate. A few have reported variability from one side of the build plate to the other. ${ }^{20,38}$ The north-south dependence of properties reported herein appears likely to be associated with orientation relative to the recoater blade. A likely mechanism for variability in the recoater direction was presented in $\mathrm{Pal}$ et $\mathrm{al}^{20}$ as illustrated by Fig. 10. As the recoater blade traverses the build tray, smaller powder particles tend to settle faster than larger powder particles. The result is that material at the end of the recoater pass (south in this paper) may be lacking in small particles, which could, in turn, result in poor packing efficiency and subsequently lower as-printed density. Regardless of the source of increased porosity, it appears that the density may be driving trends in mechanical properties, as described in the Introduction.

The secondary spatial dependence with argon flow direction is more challenging to explain. Soot and spatter particles from upstream specimens can flow with the argon causing degradation of downstream specimen properties, ${ }^{19,46}$ but that seems to be in opposition to the trend observed in this work. Future work could explore the possibility that turbulent flow or the higher flow rates near the nozzle removed small amounts of powder thereby creating voids, or that the laser quality (e.g., focus; 
Table II. Weibull parameters for data grouped by specimen print location for ultimate tensile strength and ductility. Top, small specimens; bottom, large specimens. $N$ is the number of specimens in each dataset, $A D$ is the Anderson-Darling goodness-of-fit metric, and $P$ is the calculated probability of rejecting the null hypothesis

\begin{tabular}{|c|c|c|c|c|c|c|c|}
\hline Small specimens & Location & Shape & Scale & Threshold & $\mathbf{N}$ & $\mathbf{A D}$ & $\boldsymbol{P}$ \\
\hline \multirow[t]{5}{*}{ UTS (MPa) } & Northeast (NE) & 3.3 & 17 & 161 & 63 & 0.44 & 0.235 \\
\hline & Northwest (NW) & 3.5 & 23 & 149 & 63 & 0.29 & $>0.500$ \\
\hline & Southwest (SW) & 13 & 96 & 59 & 73 & 0.24 & $>0.500$ \\
\hline & Southeast (SE) & 6.7 & 83 & 65 & 72 & 0.69 & 0.036 \\
\hline & Center (CTR) & 7.0 & 51 & 122 & 72 & 0.52 & 0.121 \\
\hline \multirow[t]{5}{*}{ Ductility (\%) } & Northeast (NE) & 3.2 & 2.8 & 1.9 & 63 & 0.41 & 0.294 \\
\hline & Northwest (NW) & 2.1 & 1.6 & 2.5 & 63 & 0.21 & $>0.500$ \\
\hline & Southwest (SW) & 3.5 & 1.8 & 1.4 & 73 & 0.61 & 0.08 \\
\hline & Southeast (SE) & 2.8 & 1.9 & 1.1 & 72 & 0.89 & 0.017 \\
\hline & Center (CTR) & 2.7 & 2.6 & 1.6 & 72 & 1.2 & $<0.005$ \\
\hline \multirow[t]{2}{*}{ Small specimens } & & & & & & & \\
\hline & Location & Shape & Scale & Threshold & $\mathbf{N}$ & AD & $\boldsymbol{P}$ \\
\hline \multirow[t]{4}{*}{ UTS (MPa) } & Northeast (NE) & 2.6 & 22 & 185 & 34 & 0.40 & 0.354 \\
\hline & Northwest (NW) & 1.8 & 14 & 192 & 48 & 0.23 & $>0.500$ \\
\hline & Southwest (SW) & 1.5 & 11 & 190 & 48 & 1.0 & 0.013 \\
\hline & Southeast (SE) & 2.5 & 22 & 178 & 46 & 0.93 & 0.015 \\
\hline \multirow[t]{4}{*}{ Ductility (\%) } & Northeast (NE) & 1.2 & 1.4 & 2.9 & 34 & 0.87 & 0.027 \\
\hline & Northwest (NW) & 1.3 & 1.6 & 3.0 & 48 & 1.3 & $<0.005$ \\
\hline & Southwest (SW) & 1.3 & 1.5 & 3.0 & 48 & 0.78 & 0.045 \\
\hline & Southeast (SE) & 1.4 & 1.9 & 2.4 & 46 & 1.8 & $<0.005$ \\
\hline
\end{tabular}

Build 1 NW
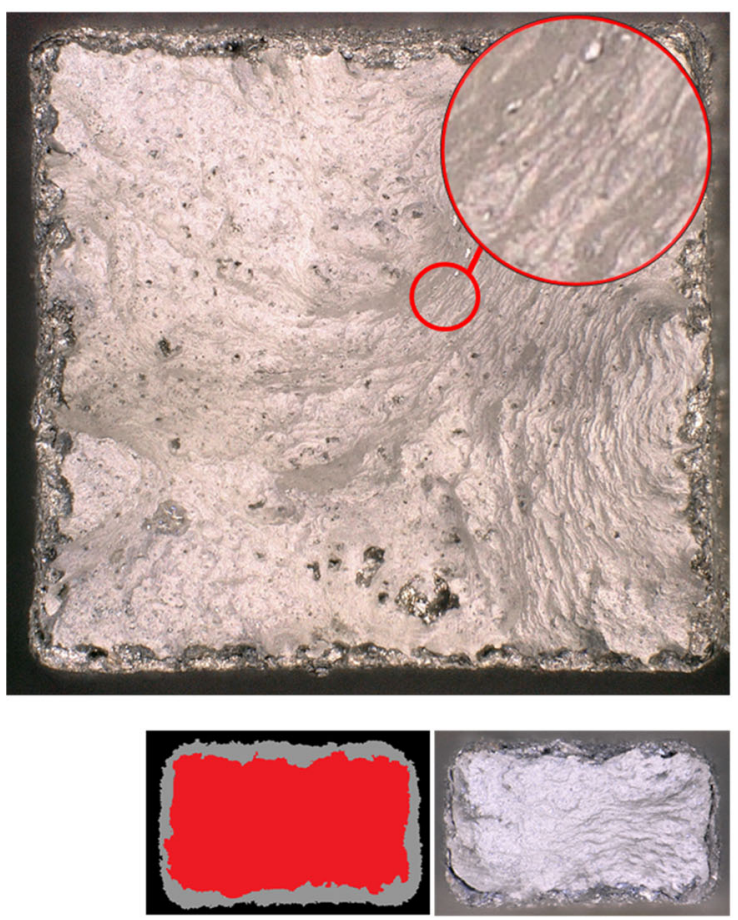

Build 7 SE
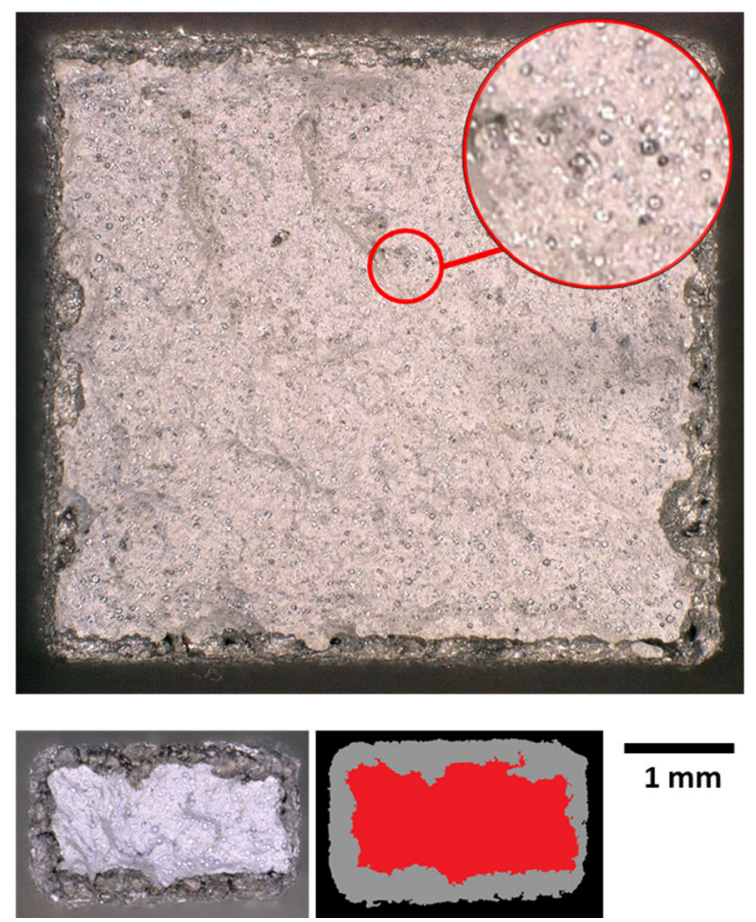

$1 \mathrm{~mm}$

Fig. 7. Typical fracture surfaces of large tensile bars for one large and one small tensile bar from build plates 1 and 7 . An inset on the large tensile bars shows the lack of voids and steps in build 1. In build 7, the inset shows many small pores. Small specimens at the bottom have corresponding images colored by interior (red) and crust (gray). The crust is much more significant for small specimens (Color figure online). 

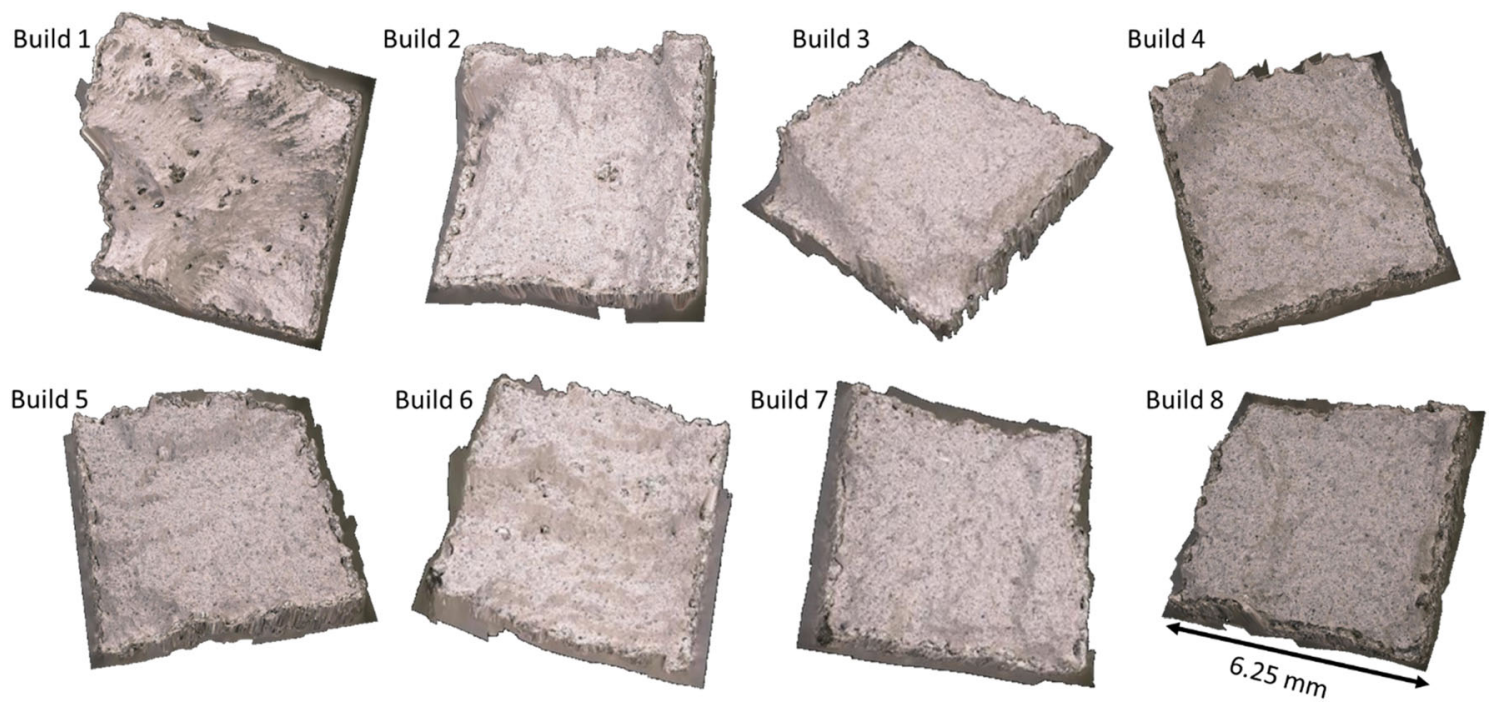

Fig. 8. Three-dimensional projections of a few large tensile bar fracture surfaces. The tortuosity of the fracture surfaces appears correlated to the mechanical properties and density.

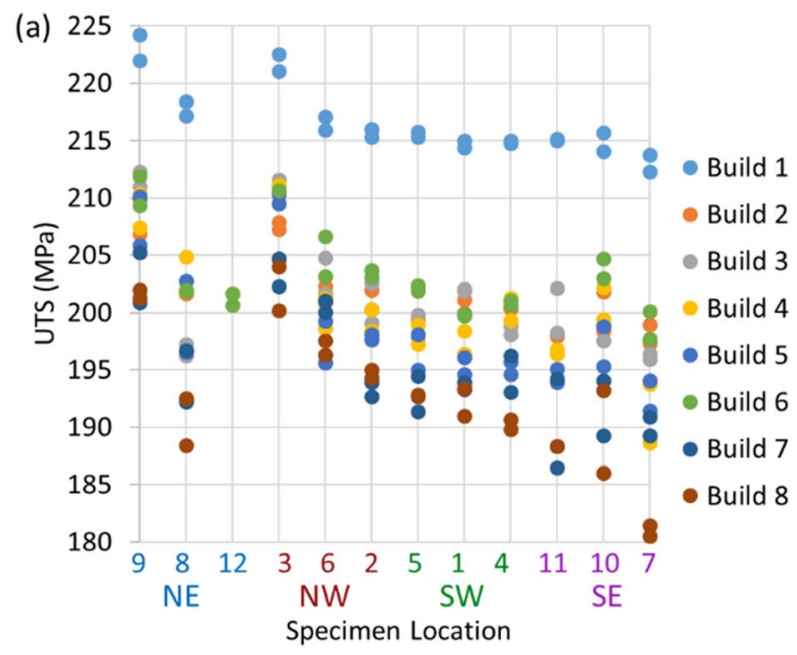

(b) Northwest

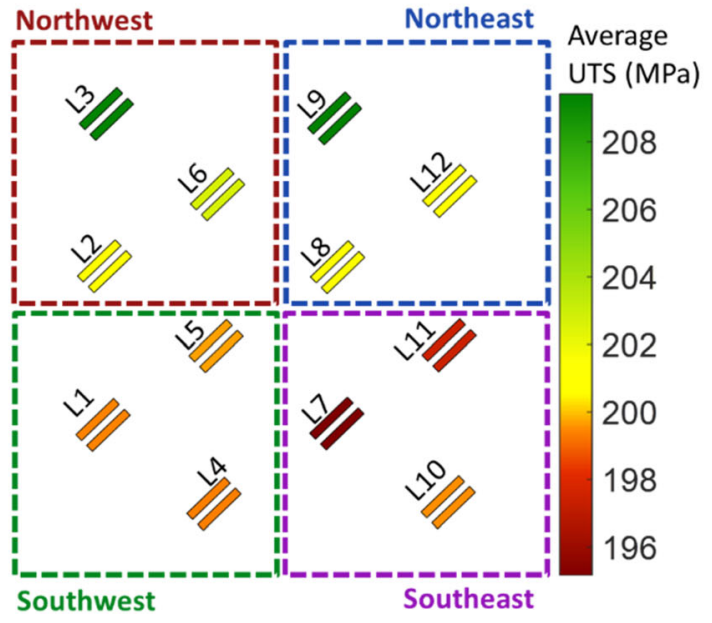

Fig. 9. (a) Plot of ultimate tensile strength vs large specimen location. Some locations are clearly stronger than others. (b) Color map of average strength values vs location on the build plate. The trend of low strength in the southeast is maintained, but strength does not monotonically decrease to that corner (Color figure online). (a) Powder coating direction

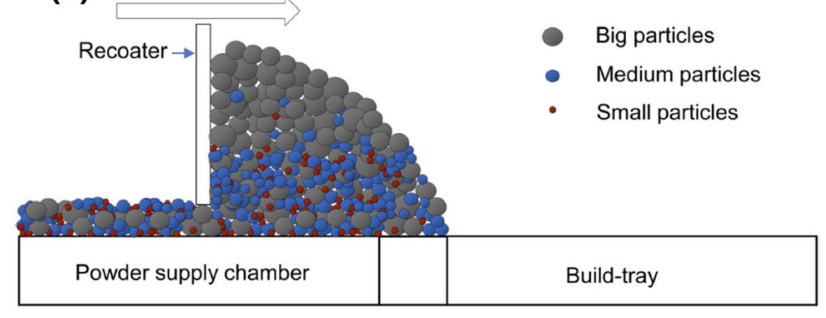

(b)

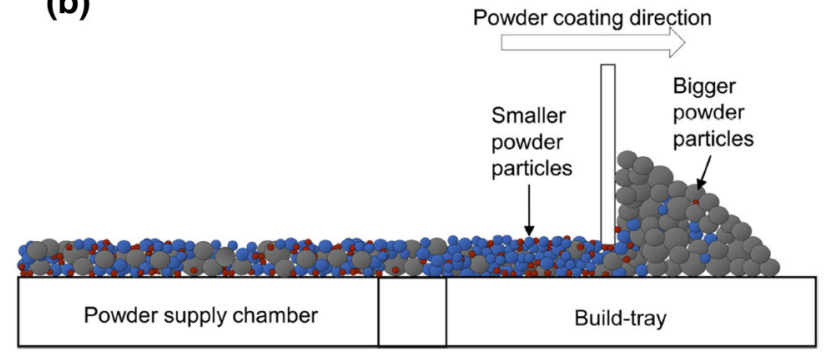

Fig. 10. As the recoater traverses the build tray, smaller particles tend to fall more quickly than large particles. The result is that at the end of a pass, fewer small particles remain, leading to lower densities as observed at the south end of the build plates in this paper. Figure used in accordance with creative commons license from (Ref. 20).

delivered power density) was itself spatially dependent.

\section{Effect of Powder Reuse}

The change in properties associated with powder reuse in the build plate sequence could be an effect of particle size similar to Pal et al. ${ }^{20}$ Powder reuse tends to decrease the proportion of fine particles in the powder. ${ }^{19}$ Most of the trends with build plate 

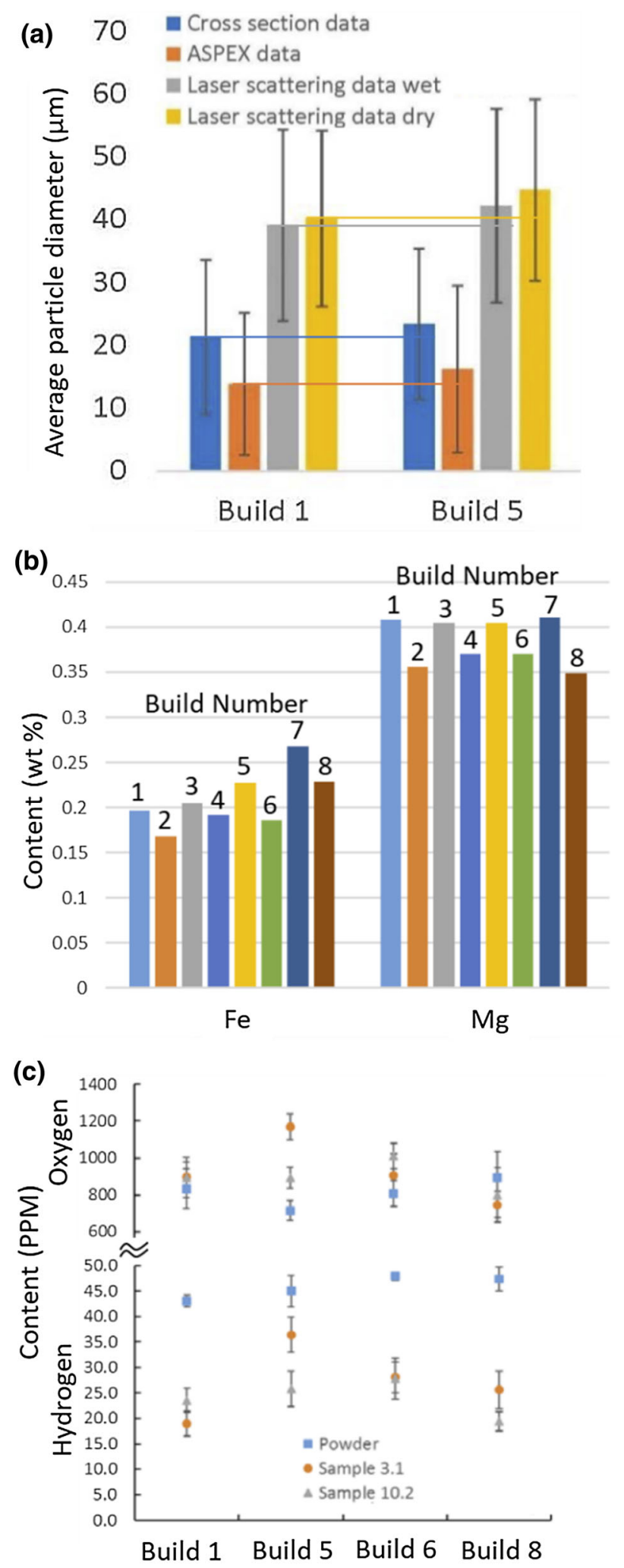

Fig. 11. (a) Average particle diameters of powder for builds 1 and 5 measured by four different techniques. (b) Composition of $\mathrm{Fe}$ and $\mathrm{Mg}$ in all 8 build plates. (c) Hydrogen and oxygen content of four selected build plates (Color figure online).

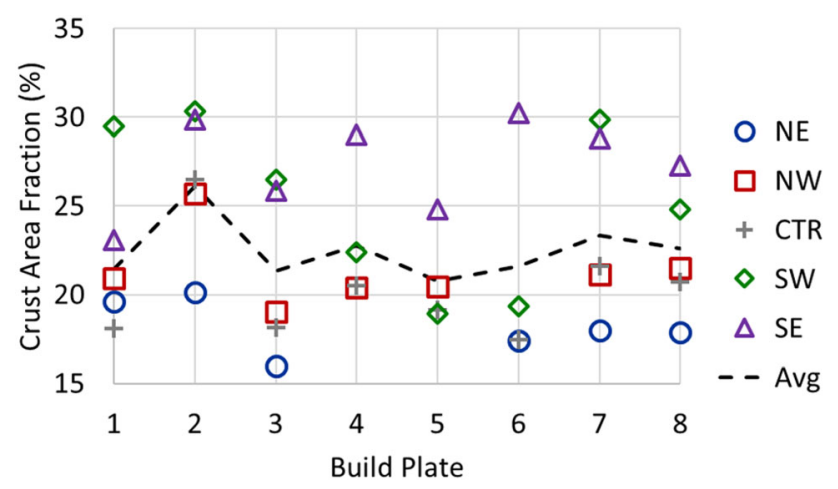

Fig. 12. Effective cross-sectional area (crust subtracted) of small tensile bars versus build plate and location.

(and powder reuse) appear to be at least qualitatively consistent with density changes. To further explore the possibility of a powder size dependence on powder recycling, we compared the average and standard deviation of powder size for builds 1 and 5 , each measured by four different techniques, as shown in Fig. 11a. While each technique provided a different bias on estimate of the powder size, across all four techniques a trend was consistent: build 5 had a $10-20 \%$ higher average particle size than build 1 . The hypothesis of changing powder size distributions with powder reuse is consistent with observed density changes, but this is far from definitive.

While particle size and surface roughness may change due to powder reuse, it appears that compositional changes in the powder could be an even more significant factor. Several previous studies have explored the effects of powder reuse on factors of chemistry and impurity content. ${ }^{19,23,47}$ In the present study, the amount of $\mathrm{Fe}$ and $\mathrm{Mg}$ in the alloy was measured using inductively coupled plasma mass spectrometry for all 8 build plates (Fig. 11b), with only seemingly minor and inconsistent fluctuations. Si content and grain structure were also shown not to change significantly between builds. ${ }^{36}$ Moisture in powder can cause porosity in AlSi10Mg associated with elevated levels of hydrogen and oxygen content. ${ }^{23,35,48}$ The oxygen and hydrogen content of four build plates, obtained from LECO ${ }^{\circledR}$ analysis, ${ }^{49}$ is presented in Fig. 11c. This figure shows measurements from the input powder and from two large tensile specimens at opposite corners of each build plate. The amount of hydrogen measured in these samples, $\sim 30 \mathrm{ppm}$ is fairly high considering that the solubility of hydrogen in molten aluminum is only $14 \mathrm{ppm}$ and drops with temperature. ${ }^{50}$ Build plate 1 has lower levels of hydrogen than the other build plates; however, the trends in hydrogen content do not fully agree with trends in density or mechanical properties pre- 
sented in this work. Furthermore, the location dependence cannot be explained well by hydrogen content since large tensile bars at location 3 (one of the strongest, most dense locations) appear to have more hydrogen than one of the least dense specimen locations (location 10). The effect of oxygen content is unclear with build plate 1 exhibiting roughly the same amount of oxygen as the other build plates.

One significant exception to the powder reuse trend is the strength and ductility of small samples from build plate 2 which seem to be significantly weaker and more brittle than subsequent builds. Detailed measurements of the surface crust for each build suggested that build 2's small specimens suffered from a particularly thick crust, as illustrated in Fig. 7 and quantified in Fig. 12. The thicker crust for build 2 was likely responsible for the lower strength and ductility (for examples of detailed analysis of the effect of surface topography on strength and ductility see Refs. 13 and 14). However, we do not yet know the source of this temporarily-degraded surface topography. The possibility of build-to-build variation in surface roughness, explored previously by our group for 17-4PH stainless steel, ${ }^{15}$ illustrates the need for systematic parametric monitoring and quality control for surface topography.

\section{Importance of Statistical Methods}

The Weibull analysis shown in this paper highlights the need for statistical measurements of AM properties. If only a few specimens were tested, the differences between build plates might not be apparent at all. Furthermore, Weibull statistics can provide threshold material properties to use in design. The lack of a Weibull threshold and the large scatter of the strength of small tensile bars indicates that the flaws in these specimens, whether it be voids or surface crust effects, are a substantial fraction of the gage dimension. As such, it is recommended that AlSi10Mg with these very high porosity levels not be used for components with such small cross sections when strength is important. The Weibull threshold approach demonstrated herein is useful for quantifying worst-case material properties for design. This statistical approach has been used on conventional materials, ${ }^{51}$ and it is starting to be used by the additive manufacturing community as well..$^{52}$ of course, statistical design values will be dependent on material, size, and processing. Consequently, it may be possible to create structures with no lower bound on strength, even when analyzing statistically large datasets.

This work has focused on powder reuse, buildplate location, and sample size effects, which seem to impact mechanical properties primarily through porosity and surface crust (and possibly other microstructural characteristics that seem less dominant here). Conclusively quantifying the convo- luted effects of each of these multiple phenomena will require multivariate statistical analyses or other advanced machine learning approaches.

\section{On the Origin of the Size-Dependent Properties}

Size effects of mechanical properties in AM have been more thoroughly investigated in stainless steel by Roach et al. ${ }^{14}$ The biggest factor driving size effects on as-printed samples is often the surface crust which takes up a larger fraction of the volume for smaller samples. Note that surface crust is not an intrinsic feature of the material itself, but a property of the printed part. Its effect is avoided in other studies that produce test coupons by postprint machining. In corollary, the present reported values for strength and ductility are not true material properties, but only effective properties of the as-printed part at a specific size. Unfortunately, aside from costly and time-consuming explicit elastoplastic finite element modeling (Ref. 14), a clear method to quantitatively predict surface crust effects on strength and ductility of AM components is still lacking. As a result, AM structural designs that ignore the surface crust effect and incorporate only true material properties can severely overestimate the performance characteristics of the part. Furthermore, size dependence through crust, porosity, and microstructure effects is dependent on the material (e.g., steel versus aluminum) and print parameters. Improved methods to measure and account for surface crust will be necessary to take advantage of the complex geometries made possible by AM.

\section{CONCLUSION}

Weibull analyses of AlSi10Mg data show that ultimate tensile strength and ductility degrade with powder reuse likely due to widespread porosity. Observed spatial variation in density, strength, ductility, and Charpy impact toughness indicates that recoater direction plays a major role, likely through powder size distribution. These trends may not have been obvious without the large number of samples tested here, affording statistical analysis. The approach to Weibull statistics used here can inform design margins in AM designs by identifying size-dependent material property thresholds.

At the levels seen here, widespread porosity (i.e., density) appears to be a significant factor in the toughness, strength, and ductility of AM AlSi10Mg. The differences between small and large tensile bars indicates that surface crust may also play a significant role, particularly for small specimens. The difference in widespread porosity with location on build plate is likely due to powder size distribution. Powder size and moisture in powder likely impact the density and mechanical property changes seen with powder reuse. 


\section{ACKNOWLEDGEMENTS}

The authors were supported by a Laboratory Directed Research and Development (LDRD) program at Sandia National Laboratories. Laboratory facilities were provided in part by the Center for Integrated Nanotechnologies. The authors thank Todd Huber, Aron Robbins, John Laing, and Zachary Casias for laboratory support. We would also like to thank Ian Campbell and Pin Yang for fruitful discussions. Sandia National Laboratories is a multimission laboratory managed and operated by National Technology and Engineering Solutions of Sandia LLC, a wholly owned subsidiary of Honeywell International Inc., for the U.S. Department of Energy's National Nuclear Security Administration under contract DE-NA0003525.

\section{CONFLICT OF INTEREST}

On behalf of all authors, the corresponding author states that there is no conflict of interest.

\section{OPEN ACCESS}

This article is licensed under a Creative Commons Attribution 4.0 International License, which permits use, sharing, adaptation, distribution and reproduction in any medium or format, as long as you give appropriate credit to the original author(s) and the source, provide a link to the Creative Commons licence, and indicate if changes were made. The images or other third party material in this article are included in the article's Creative Commons licence, unless indicated otherwise in a credit line to the material. If material is not included in the article's Creative Commons licence and your intended use is not permitted by statutory regulation or exceeds the permitted use, you will need to obtain permission directly from the copyright holder. To view a copy of this licence, visit http://creativecommons.org/licenses/by/4.0/.

\section{REFERENCES}

1. I. Rosenthal, A. Stern, and N. Frage, Metallography. Microstruct. Anal. 3, 448-453. (2014).

2. Y. Ding, J. Muñiz-Lerma, M. Trask, S. Chou, A. Walker, and M. Brochu, MRS Bull. 41, 745-751. (2016).

3. J. Wu, X. Wang, W. Wang, M. Attallah, and M. Loretto, Acta Mater. 117, 311-320. (2016).

4. B. Chen, S. Moon, X. Yao, G. Bi, J. Shen, J. Umeda, and K. Kondoh, Scripta Mater. 141, 45-49. (2017).

5. M. Orme, I. Madera, M. Gschweitl, and M. Ferrari, Designs 2, 51. (2018).

6. B. Liu, C. Jiang, G. Li, and X. Huang, Comput. Methods in Appl. Mech. Eng. 360, 112786. (2020).

7. P. Zhang, J. Liu, and A.C. To, Scripta Mater. 135, 148-152. (2017).

8. J. Faludi, M. Baumers, I. Maskery, and R. Hague, J. Ind. Ecol. 21, S144-S156. (2017).

9. N.E. Gorji, P. Saxena, M. Corfield, A. Clare, J.-P. Rueff, J. Bogan, P.G. González, M. Snelgrove, G. Hughes, and R. O'Connor, Mater. Charact. 161, 110167. (2020).

10. F. Ahmed, U. Ali, D. Sarker, E. Marzbanrad, K. Choi, Y. Mahmoodkhani, and E. Toyserkani, J. Mater. Process. Technol. 278, 116522. (2020).
11. A.T. Sutton, C.S. Kriewall, S. Karnati, M.C. Leu, and J.W. Newkirk, Additive Manufacturing 32, 100981. (2020).

12. A.T. Sutton, C.S. Kriewall, S. Karnati, M.C. Leu, J.W. Newkirk, W. Everhart, B. Brown, Additive Manufacturing, 36101439 (2020).

13. A.D. Dressler, E.W. Jost, J.C. Miers, D.G. Moore, C.C. Seepersad, and B.L. Boyce, Addit. Manuf. 28, 692-703. (2019).

14. A.M. Roach, B.C. White, A. Garland, B.H. Jared, J.D. Carroll, and B.L. Boyce, Additive Manufac. 32, 101090. (2020).

15. B.C. Salzbrenner, J.M. Rodelas, J.D. Madison, B.H. Jared, L.P. Swiler, Y.-L. Shen, and B.L. Boyce, J. Mater. Process. Technol. 241, 1-12. (2017).

16. E. Santecchia, S. Spigarelli, M. Cabibbo, Metals, 10 (2020).

17. A. Hadadzadeh, C. Baxter, B.S. Amirkhiz, and M. Mohammadi, Addit. Manuf. 23, 108-120. (2018).

18. F. Del Re, V. Contaldi, A. Astarita, B. Palumbo, A. Squillace, P. Corrado, and P. Di Petta, Int. J. Adv. Manufac. Technol. 97, 2231-2240. (2018).

19. M.J. Heiden, L.A. Deibler, J.M. Rodelas, J.R. Koepke, D.J. Tung, D.J. Saiz, and B.H. Jared, Addit. Manuf. 25, 84-103. (2019).

20. S. Pal, N. Gubeljak, T. Bončina, R. Hudák, T. Toth, J. Zivcak, G. Lojen, N. Leben, and I. Drstvenšek, Int. J. Adv. Manufac. Technol. 112, 1159-1170. (2021).

21. T. Hirata, T. Kimura, T. Nakamoto, Mater. Sci. Eng.: A, 772 (2020).

22. O.H. Famodimu, M. Stanford, C.F. Oduoza, and L. Zhang, Front. Mech. Eng. 13, 520-527. (2018).

23. A. Raza, T. Fiegl, I. Hanif, A. MarkstrÖm, M. Franke, C. Körner, and E. Hryha, Mater. Design 198, 109358. (2021).

24. J.A. Choren, S.M. Heinrich, and M.B. Silver-Thorn, J. Mater. Sci. 48, 5103-5112. (2013).

25. M.K. Surappa, E. Blank, and J.C. Jaquet, Scr. Metall. 20, 1281-1286. (1986).

26. C.M. Laursen, S.A. DeJong, S. Dickens, A.N. Exil, D.F. Susan, J.D. Carroll, Mater. Sci. Eng.: A, 139922 (2020).

27. A.M. Gokhale, and G.R. Patel, Mater. Sci. Eng., A 392, 184190. (2005).

28. C.H. Cáceres, and B.I. Selling, Mater. Sci. Eng., A 220, 109116. (1996).

29. B.L. Boyce, B.C. Salzbrenner, J.M. Rodelas, L.P. Swiler, J.D. Madison, B.H. Jared, and Y.L. Shen, Adv. Eng. Mater. 19, 1700102. (2017).

30. N.M. Heckman, T.A. Ivanoff, A.M. Roach, B.H. Jared, D.J. Tung, H.J. Brown-Shaklee, T. Huber, D.J. Saiz, J.R. Koepke, and J.M. Rodelas, Mater. Sci. Eng.: A 772, 138632. (2020).

31. N. Takata, H. Kodaira, A. Suzuki, and M. Kobashi, Mater. Charact. 143, 18-26. (2018).

32. ASTM International, F3318-18 Standard for Additive Manufacturing - Finished Part Properties - Specification for AlSi10Mg with Powder Bed Fusion - Laser Beam, 2018.

33. P. Yang, L.A. Deibler, D.R. Bradley, D.K. Stefan, and J.D. Carroll, J. Mater. Res. 33, 4040-4052. (2018).

34. P. Yang, M.A. Rodriguez, L.A. Deibler, B.H. Jared, J. Griego, A. Kilgo, A. Allen, and D.K. Stefan, J. Mater. Res. 33, 1701-1712. (2018).

35. C. Weingarten, D. Buchbinder, N. Pirch, W. Meiners, K. Wissenbach, and R. Poprawe, J. Mater. Process. Technol. $221,112-120$. (2015).

36. C.B. Finfrock, A. Exil, J.D. Carroll, and L. Deibler, Metallography. Microstruct. Anal. 7, 443-456. (2018).

37. ASTM International, E23-12c, Standard Test Methods for Notched Bar Impact Testing of Metallic Materials, 2018.

38. L. Minitab, https://support.minitab.com/en-us/minitab/18/he lp-and-how-to/modeling-statistics/reliability/how-to/distribu tion-overview-plot-right-censoring/methods-and-formulas/ parametric-methods-and-formulas/distribution-functions/, accessed 30 April 2021.

39. T.W. Anderson, Anderson-Darling Tests of Goodness-of-Fit, in International Encyclopedia of Statistical Science. ed. by M. Lovric (Springer, Berlin Heidelberg, Berlin, Heidelberg, 2011), pp. 52-54. 
40. T.W. Anderson, and D.A. Darling, Ann. Math. Stat. 23(193212), 120. (1952).

41. J.L. Romeu, RAC START RIAC, 10 (2003).

42. R.A. Lockhart, and M.A. Stephens, J. Royal Statistical Soc. Series B (Methodological) 56, 491-500. (1994).

43. J. Dzugan, M. Seifi, R. Prochazka, M. Rund, P. Podany, P. Konopik, and J.J. Lewandowski, Mater. Charact. 143, 94 109. (2018).

44. E. Pehlivan, M. Roudnicka, J. Dzugan, M. Koukolikova, V. Králík, M. Seifi, J.J. Lewandowski, D. Dalibor, and M. Daniel, Additive Manufact. 35, 101403. (2020).

45. T. Fiegl, M. Franke, and C. Körner, Opt. Laser Technol. 111, 51-57. (2019).

46. F. Wirth, A. Frauchiger, K. Gutknecht, M. Cloots, Influence of the Inert Gas Flow on the Laser Powder Bed Fusion (LPBF) Process, (2021).

47. A. Soltani-Tehrani, J. Pegues, and N. Shamsaei, Additive Manufacturing 36, 101398. (2020).
48. T.A. McFalls, Mechanical Engineering, Masters Thesis (2018).

49. M.T. Crewe, P.C. Lopes, S.C. Moura, J.A. Sampaio, O.V. Bustillos, INAC 2011: International nuclear atlantic conference. Associacao Brasileira de Energia Nuclear, Rio de Janeiro, RJ (Brazil), Belo Horizonte, MG (Brazil) (2011).

50. J.-P. Harvey, and P. Chartrand, Metall. Mater. Trans. B. 41, 908-924. (2010).

51. MMPDS-04: Metallic materials properties development and standardization (MMPDS), Federal Aviation Administration; Battelle Memorial Institute, 2008.

52. NASA, MSFC-STD-3716, Standard for Additively Manufactured Spaceflight Hardware by Laser Powder Bed Fusion in Metals 2017.

Publisher's Note Springer Nature remains neutral with regard to jurisdictional claims in published maps and institutional affiliations. 